\author{
Original
}

\title{
Biosynthesis of PVA encapsulated silver nanoparticles
}

\author{
Sharmila Chandran ${ }^{\mathrm{a}, *}$, Vinuppriya Ravichandran ${ }^{\mathrm{b}}$, Selvi Chandran ${ }^{\mathrm{b}}$, Jincy Chemmanda ${ }^{\mathrm{b}}$, \\ Bellan Chandarshekar ${ }^{\mathrm{c}}$ \\ ${ }^{a}$ Assistant Professor, Department of Physics, PSGR Krishnammal College for Women, Coimbatore 641004, Tamil Nadu, India \\ ${ }^{\mathrm{b}}$ Research Scholar, Department of Physics, PSGR Krishnammal College for Women, Coimbatore 641004, Tamil Nadu, India \\ ${ }^{\mathrm{c}}$ Assistant Professor, Department of Physics, Kongunadu College of Arts and Science, Coimbatore 641029, Tamil Nadu, India
}

Received 28 January 2016; accepted 25 July 2016

Available online 13 October 2016

\begin{abstract}
Green synthesis of metal nanoparticles is an important technique in the methods of eco-friendly nanoparticle production. The synthesis of silver nanoparticles was accomplished using Ocimum sanctum leaf extract at room temperature. These particles were then encapsulated with polyvinyl alcohol (PVA) polymer matrix. The presence of silver was confirmed by different characterization techniques such as UV-vis spectroscopy, Fourier transform infrared spectroscopy (FTIR) and X-Ray Diffraction (XRD). Scanning electron microscopic (SEM) images of the synthesized powder shows spherical shaped silver nanoparticles embedded in sponge-like polymer matrix. The energy dispersive X-ray analysis confirms the presence of elemental silver along with iron signal. Energy dispersive signal corresponding to elemental iron has been attributed to $O$. sanctum plant. The silver nanoparticles in PVA matrix thus obtained shows high antibacterial activity against gram positive Staphylococcus aureus (S. aureus) and gram negative Escherichia coli (E. coli) water borne bacteria. The inhibition zone against $S$. aureus and E. coli were also calculated.

(C) 2016 Universidad Nacional Autónoma de México, Centro de Ciencias Aplicadas y Desarrollo Tecnológico. This is an open access article under the CC BY-NC-ND license (http://creativecommons.org/licenses/by-nc-nd/4.0/).
\end{abstract}

Keywords: Silver nanoparticles; Ocimum sanctum; PVA; Antibacterial studies

\section{Introduction}

Research on nanoparticles is currently an area of intense scientific interest due to its wide range of applications (Abdulrahman, Krajczewski, Aleksandrowska, \& Kudelski, 2015; Park, Lee, \& Lee, 2016; Taylor, Coulombe, et al., 2013; Yahyaei et al., 2016). In spite of being the size of the ultrafine particles individual molecules are usually not referred to as nanoparticles (Hewakuruppu et al., 2013). Nanoparticles form a bridge between bulk materials and atomic/molecular structures. Nanoparticles do not need to have constant physical properties, they may vary (Taylor, Otanicar, et al., 2013). The size dependent property such as quantum confinement can be observed in semiconductor particles, surface plasmon resonance is found in some metal particles and super magnetism is observed in magnetic materials (Taylor, Otanicar, \& Rosengarten, 2012).

\footnotetext{
* Corresponding author.

E-mail addresses: sharmilakshu@gmail.com, sharmilac@psgrkc.com (S. Chandran).

Peer Review under the responsibility of Universidad Nacional Autónoma de México.
}

Nowadays, metallic nanoparticles are the focus of interest because of their huge potential in nanotechnology (Mody, Siwale, Singh, \& Mody, 2010; Salunke, Sawant, Lee, \& Kim, 2016). Metallic nanoparticles have been embraced by industrial sectors because of their applications in the field of electronic storage systems (Kang, Risbud, Rabolt, \& Stroeve, 1996), biotechnology (Pankhurst, Connolly, Jones, \& Dobson, 2003), magnetic separation and pre-concentration of target analysts, targeted drug delivery (Dobson, 2006; Rudge et al., 2001) and vehicles for gene and drug delivery. With a wide range of applications available, these particles have the potential to make a significant impact on society.

Silver nanoparticles have some advantages over other nanoparticles because they are reported to be non-toxic to human and most effective against bacteria, viruses and other eukararyolitic micro-organisms at a very low concentration, without any known side effects (Chauhan, Gupta, \& Prakash, 2012). Many efforts have been taken to incorporate silver nanoparticles into a wide range of medical devices, such as bone cement, surgical instruments, surgical masks (Valente, Gaspar, Antunes, Countinho, \& Correia, 2013); however, it has also been shown that ionic silver in the right quantities is suitable in treating 
wounds (Atiyeh, Costagliola, Hayek, \& Dibo, 2007; Chen \& Schluesener, 2008; Qin, 2005).

There are many approaches available for the synthesis of silver nanoparticles which include the chemical method (Sun, Yin, Mayers, Herricks, \& Xia, 2002), the electrochemical method (Yin, Ma, Wang, \& Chen, 2003), the radiation method (Dimitrijevic, Bartels, Jonah, Takahashi, \& Rajh, 2001), the photochemical method (Callegari, Tonti, \& Chergui, 2003), and the biological techniques (Huang et al., 2016; Naik, Stringer, Agarwal, Jones, \& Stone, 2002). Among these methods for silver preparation, plant mediated biomimetic synthesis of silver nanoparticles is considered as widely acceptable technology for rapid production of silver nanoparticles for successfully meeting the excessive needs and current market demands. When a metal core is capped with a plant extract then these biomaterials will act as a more effective therapeutic agent, compared to the nanomaterials synthesized by any chemical method (Mittal, Chisti, \& Banerjee, 2013). Phytochemicals, such as ursolic acid, flavonoids, saccharides and proteins, present in plant extract are responsible for the reduction of silver ions (Bhaumik et al., 2015); hence this bioinspired synthesis of nanomaterials is highly advantageous as a natural and cost effective resource.

Recently many plants have gained importance because of their unique properties. These plants have versatile applicability in various developing fields of research and development. Among these medicinal plants, the tulsi leave (Ocimum sanctum) plant have high rate of medicinal value. Studies have shown that silver nanoparticles prepared from tulsi leaves were used in different applications (Sharma, Yngard, \& Lin, 2009; Zhang, Wu, Chen, \& Lin, 2009). The leaves have a long history of medicinal uses. $O$. sanctum leaves act as antifertility, anticancer, antidiabetic, antifungal \& antimicrobial agents (Philip \& Unni, 2011). Even though silver nanoparticles reduced by $O$. sanctum leaves exhibit high therapeutic potential, using silver alone is a challenging task for applications in food industry and pharmaceutical technology. Hence attention has been given to polymer metal composite to potentiate the protection of biological active compounds from degradation, control drug release, and improve absorption of the therapeutic agent (Ahmed \& Aljaeid, 2016).

The aim of the present study is to synthesis eco-friendly silver nanoparticles by green synthesis from fresh leaves of $O$. sanctum and to encapsulate these silver nanoparticles in a PVA matrix. The synthesis of nanoparticles from plant extract is cost effective and does not require much equipment. The PVA encapsulated silver nanoparticles synthesized from such technique are stable for several months and can be stored at room temperature without any special attention. Different characterization techniques were carried out to confirm the existence of silver nanoparticles.

\section{Materials and methods}

\subsection{Preparation of leaf extract}

Fresh leaves of $O$. sanctum were collected from local residence around Coimbatore, Tamil Nadu, India. The leaves were washed thoroughly several times with double distilled water. Leaf extract used for the synthesis was prepared by weighing
$20 \mathrm{~g}$ of fresh leaves. The freshly cut leaves were grained by mortar and pestle. The crushed leaves were added to $200 \mathrm{ml}$ of double distilled water and boiled at $100{ }^{\circ} \mathrm{C}$ in an Erlenmeyer flask for $15 \mathrm{~min}$. The leaf extract was filtered through Whatman No.1 filter paper.

\subsection{Biosynthesis of silver nanoparticles}

Silver nanoparticles from plant extract were synthesized by using $100 \mathrm{ml}$ of $1 \times 10^{-3} \mathrm{M}$ aqueous silver nitrate (Himedia, Bangalore) with $20 \mathrm{ml}$ of leaf extract. Both were mixed at room temperature and stirred vigorously for $1 \mathrm{~h}$ in a magnetic stirrer. It was observed that the color of the mixture changed from light green to dark brown indicating the formation of silver nanoparticles.

\subsection{Preparation of silver nanoparticles in PVA matrix}

Poly Vinyl Alcohol (PVA) (Himedia, Bangalore) of $0.14 \mathrm{~g}$ was mixed with $100 \mathrm{ml}$ of double distilled water and stirred for $2 \mathrm{~h}$. The solution was then slowly added with $120 \mathrm{ml}$ of leaf extract $\mathrm{AgNO}_{3}$.

\section{4. $U V$-visible spectroscopy $(U V)$}

The formation of silver nanoparticles from the leaf extract was characterized by UV-visible Spectroscopy using a Cyber lab UV-100 double beam spectrophotometer in the wavelength range of 300-800 nm. A comparative absorption spectrum was obtained between the pure silver nanoparticles and the PVA encapsulated silver nanoparticles.

\subsection{X-ray diffraction (XRD)}

Colloidal form of silver nanoparticles in the PVA matrix was coated on a well cleaned glass substrate by drop technique and was allowed to dry at room temperature for $24 \mathrm{~h}$. The glass substrate was then characterized using SHIMADZU Lab XRD 6000 with $\mathrm{CuK} \alpha$ radiation monochromatic filter in the range $10^{\circ}-80^{\circ}$. Debye-Scherer's equation was used to calculate the particle size of silver nanoparticles.

\subsection{Fourier transform infrared spectroscopy (FTIR)}

To identify the functional groups present in the colloidal form of the PVA embedded silver nanoparticles, the Fourier transform infrared (FTIR) analysis was carried out using IR-Affinity 1, Shimadzu make FTIR Spectrometer in a wavenumber range from 500 to $3500 \mathrm{~cm}^{-1}$.

\subsection{Scanning electron microscopy (SEM)}

The PVA embedded silver nanoparticles coated on the glass substrate by drop method were characterized using a TESCAN make Scanning Electron Microscope. SEM images were taken for different magnifications. An elemental analysis was also done by energy dispersive X-ray analysis (EDAX) along with the scanning electron microscopy. 


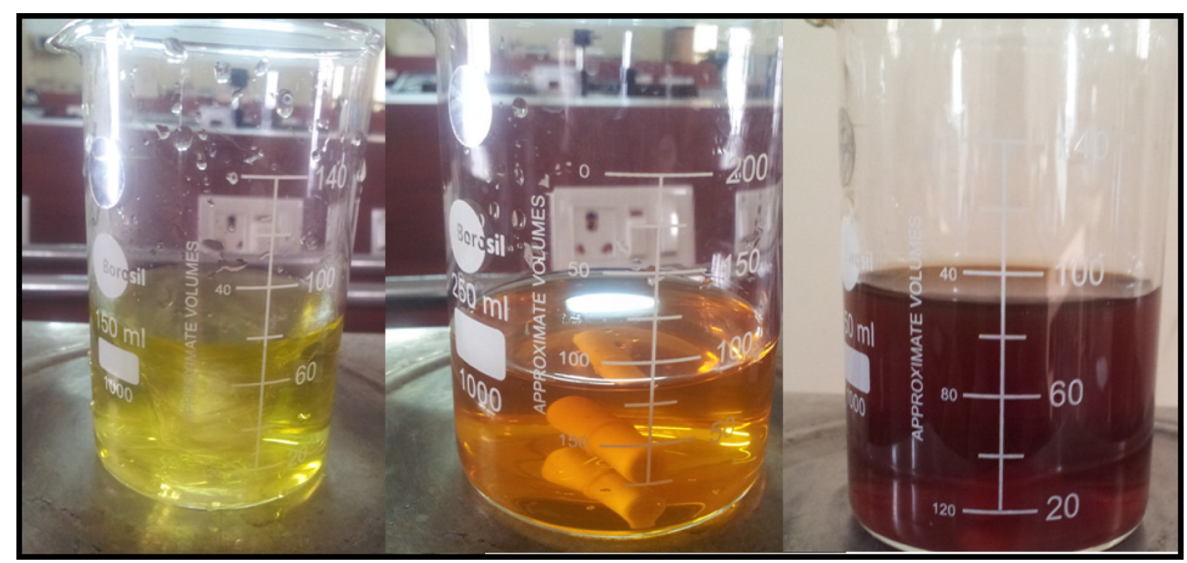

Figure 1. Increase in the color intensity of the reaction mixture with time for 5, 30 and $60 \mathrm{~min}$.

\section{Results and discussions}

\subsection{UV-visible spectroscopic analysis}

The absorption spectra of pure silver nanoparticles, and the PVA encapsulated silver nanoparticles were carried out. The reduction of silver nanoparticles using tulsi $(O$. sanctum) leaves was evidenced visually by a change in color, from light green to dark brown. Color intensity increases with increase in time. Initially when adding $1 \times 10^{-3} \mathrm{M}$ aqueous silver nitrate with $20 \mathrm{ml}$ of leaf extract, the color of the solution was found to be light green; after one hour, the color changed from reddish brown to dark brown (Fig. 1). This effect may be due to Surface Plasmon Vibration (Krasovskii \& Karavanskii, 2008; Sun \& Xia, 2002).

SPR peaks for pure silver nanoparticles were recorded for different time intervals (Fig. 2). The absorption peak at $480 \mathrm{~nm}$ appears because of the presence of silver nanoparticles, and the results are in good correlation between the earlier reported studies (Sharma, Vendamani, Pathak, \& Tiwari, 2015). The intensity of the absorption peak increases steadily as a function of time and was highest for $1 \mathrm{~h}$. The increase in intensity indicates the increase in concentration of the silver nanoparticles (Cheng, Hung, Chen, Liu, \& Young 2014). The UV-spectra recorded after $2 \mathrm{~h}$ does not show any increase in the intensity of the absorption spectrum, which shows that the reaction was completed within $2 \mathrm{~h}$ where the silver ions gets separated and settled down at the bottom of the tube from the supernatant mother liquid leaving it as a colorless solution.

A broad SPR peak was observed for the PVA encapsulated silver nanoparticles solution and the absorption spectra was observed from $450 \mathrm{~nm}$ to $480 \mathrm{~nm}$ and (Fig. 2a). The broad nature of the band might be due to the presence of polymer in the solution. The reaction mixture was stable for 3 months at room temperature without any special attention.

\subsection{X-ray diffraction analysis}

Figure 3 shows the XRD pattern for the synthesized silver nanoparticles in PVA matrix and it is observed that the particles are crystalline in nature. Strong peaks from Braggs reflection
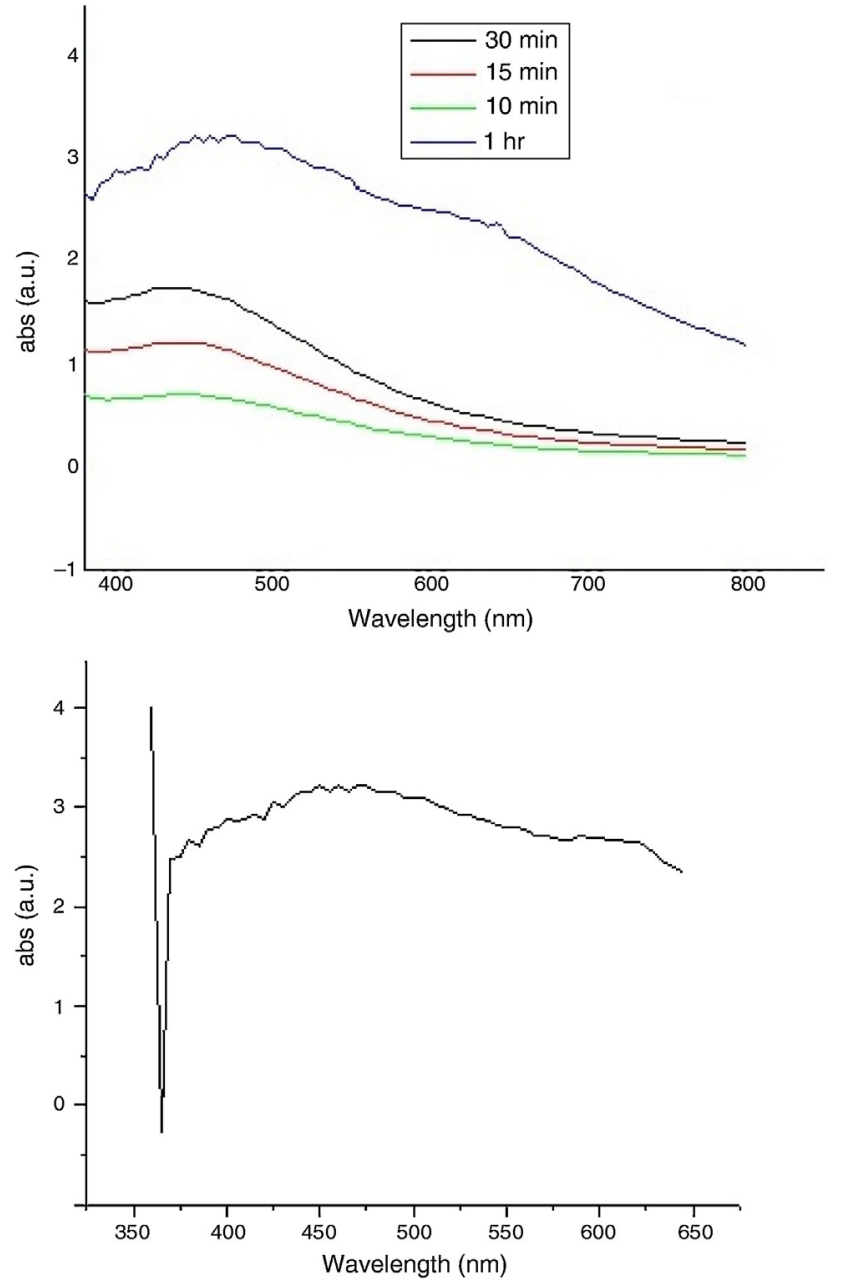

Figure 2. UV-vis absorption spectra of pure silver nanoparticles for different time intervals. (a) UV-vis absorption spectra of PVA encapsulated silver nanoparticles.

was observed in the XRD pattern at $2 \theta=12^{\circ}, 32^{\circ}$ and $38^{\circ}$. It is well known that the peaks at $2 \theta$ less than $20^{\circ}$ are due to the crystalline nature of the PVA polymer molecule. The lattice planes [101] corresponding to $2 \theta=12^{\circ}$ may be formed as a result of strong intermolecular and intramolecular hydrogen bonding 


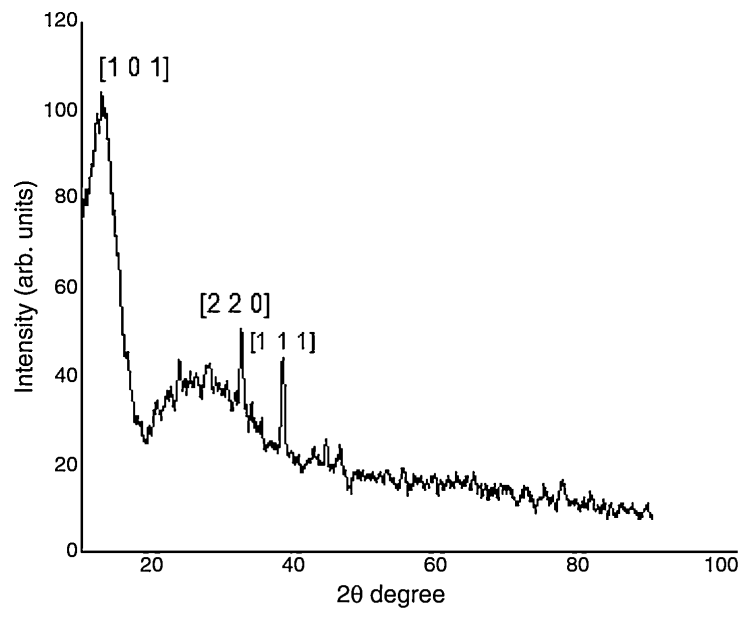

Figure 3. XRD pattern of PVA encapsulated silver nanoparticles

between the PVA chains. The X-ray diffraction peak corresponding to $38^{\circ}$ is due to the silver nanoparticles corresponding to the lattice plane [111]. The peaks at $32^{\circ}$ might be due to the presence of certain impurities while bonding between the PVA and the silver molecule (Kim, Kim, Lee, \& Kim, 1992; Guirguis \& Moselhey, 2012). The grain size of silver nanoparticles were calculated using Debye-Scherer's equation $D=K \lambda / \beta \cos \theta$, where the average grain size was found to be $20 \mathrm{~nm}$.

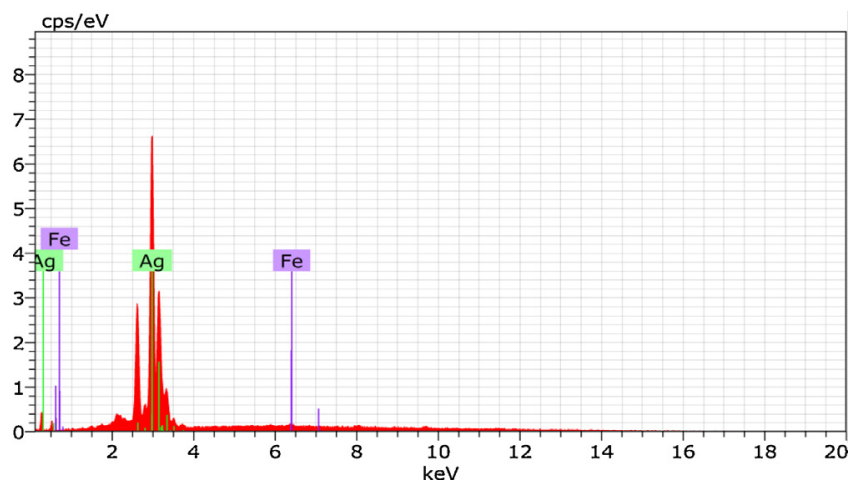

Figure 6. Energy dispersive X-ray analysis spectrum of PVA embedded silver nanoparticles.

\subsection{FTIR analysis}

FTIR spectroscopy has been proved to be a very powerful technique to study the internal structure of polymeric material and intra-molecular interaction between polymeric material and filler. The FTIR spectrum of the synthesized Ag nanoparticles in PVA matrix is shown in Figure 4. Prominent peaks were observed at $3340 \mathrm{~cm}^{-1}, 1637 \mathrm{~cm}^{-1}, 659 \mathrm{~cm}^{-1}$ to $553 \mathrm{~cm}^{-1}$. The peak observed at $3340 \mathrm{~cm}^{-1}$ indicates the presence of a hydrogen bond between the PVA polymer and leaf causing $\mathrm{OH} / \mathrm{NH}_{2}$

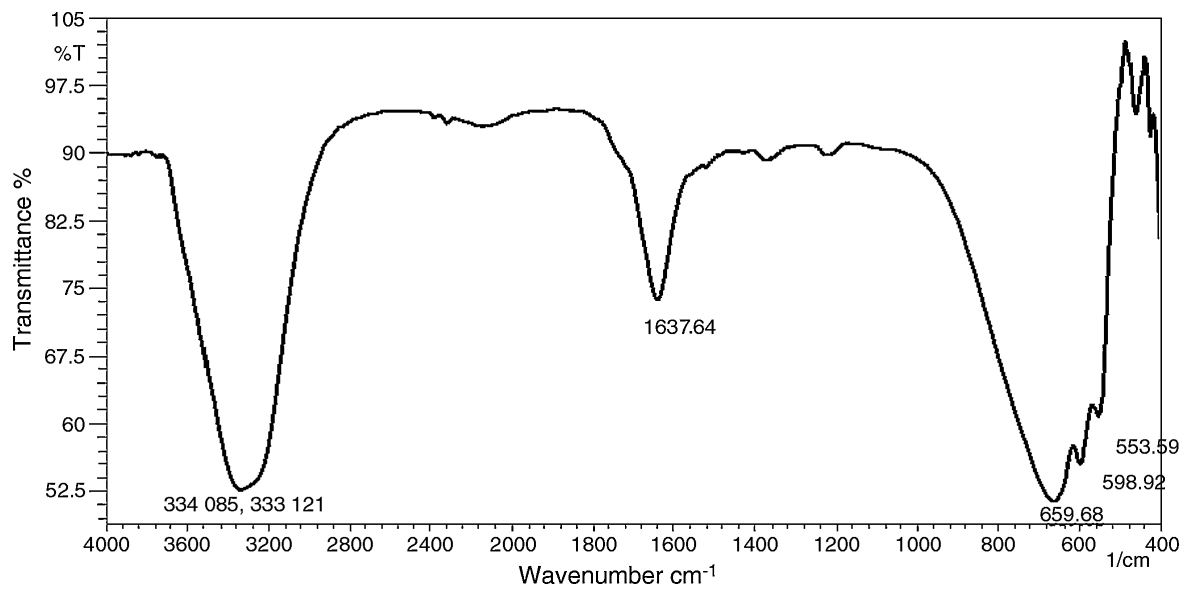

Figure 4. Fourier transform infrared spectroscopy spectrum of silver nanoparticles in PVA matrix.
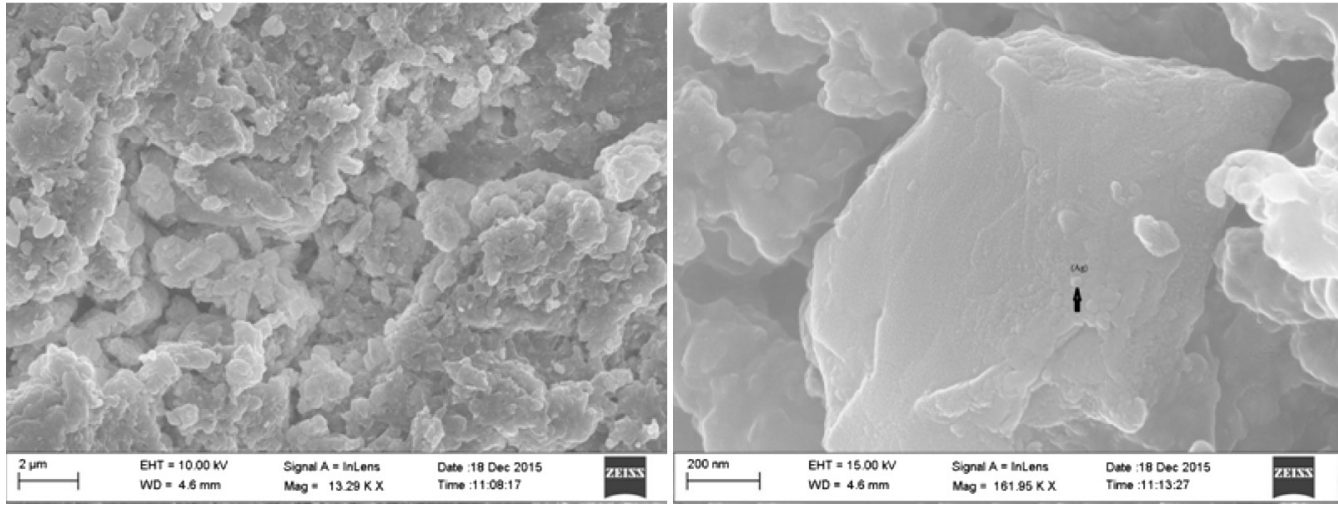

Figure 5. SEM images of silver nanoparticles in PVA matrix on different nanometric scale. 


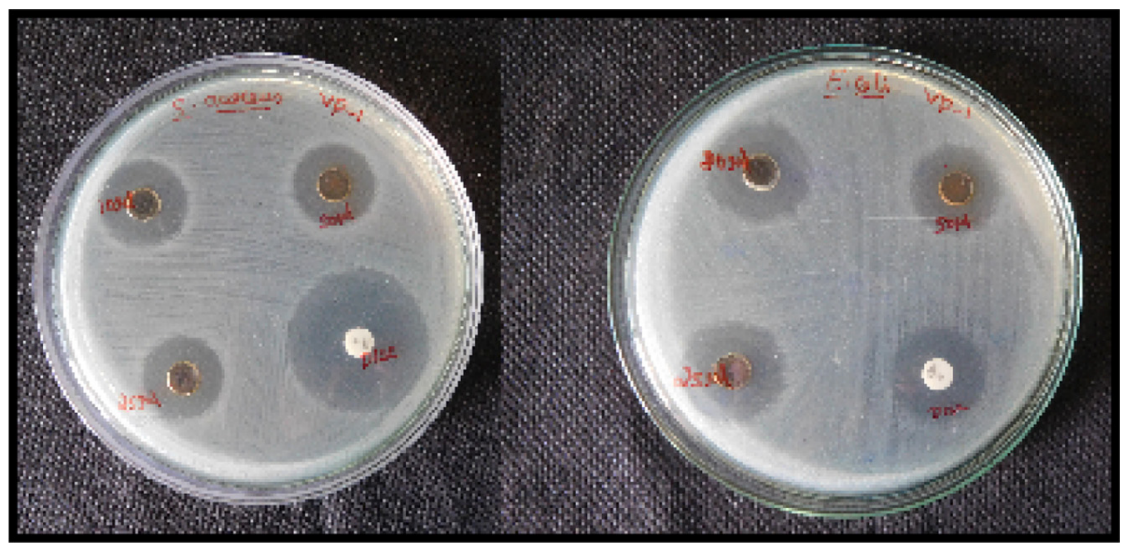

Figure 7. Appearances of inhibitory zones of PVA embedded silver nanoparticles against S. aureus and E. coli.

Table 1

EDAX elemental micro-analysis of the PVA encapsulated silver nanoparticles.

\begin{tabular}{lll}
\hline Element & Wt $\%$ & At $\%$ \\
\hline FeK-series & 2.54 & 1.33 \\
AgL-series & 97.46 & 98.67 \\
Matrix & Correction & ZAF
\end{tabular}

stretching. The peak at $1637 \mathrm{~cm}^{-1}$ may be attributed to $\mathrm{C}=\mathrm{C}$, stretching mode. The peaks from $659 \mathrm{~cm}^{-1}$ to $553 \mathrm{~cm}^{-1}$ might be caused by wagging mode of $\mathrm{OH}$ groups (Agnihotri, Mukherji, \& Mukherji, 2012; Cheng et al., 2014). The FTIR results confirm that the PVA, as a capping agent, plays an important role in the formation of silver nanoparticles.

\subsection{SEM analysis}

Morphology of the synthesized silver nanoparticles in the PVA matrix was observed from the SEM micrographs. Figure 5 shows the SEM images for different magnifications. From the graph, it is found that the spherical shaped silver nanoparticles were embedded in a sponge-like PVA matrix. The energy dispersive X-ray analysis (EDAX) reveals strong signal in the silver region and confirms the presence of silver nanoparticles (Fig. 6). Generally silver nanoparticles show optical absorption peak approximately at $3 \mathrm{keV}$ due to surface plasmon resonance (Ahmad et al., 2003). Along with silver, Fe nanoparticles were also found in the graph which might be caused by the iron content present in the $O$. sanctum leaves. The atomic weight percentage of the elements present was tabulated and is shown in Table 1.

\subsection{Antibacterial activity}

The antibacterial potential of silver has been known for many years. Antibacterial activity of silver nanoparticles was evaluated by agar disk diffusion method using Muller Hinton agar. The antibacterial effect of PVA encapsulated silver was tested against gram positive Staphylococcus aureus ( $S$. aureus) and gram negative Escherichia coli (E. coli) bacteria for different concentrations (Fig. 7). Eugenol (1-hydroxy-2methoxy-4-allylbenzene), the active constituent present in $O$.
Table 2

Zone of inhibition against gram negative and gram positive bacteria.

\begin{tabular}{llc}
\hline Concentration $(\mu \mathrm{l})$ & \multicolumn{2}{c}{ Zone of inhibition $(\mathrm{mm})$ (half diameter) } \\
\cline { 2 - 3 } Sample & E. coli & S. aureus \\
\hline 10 & 6 & 4 \\
25 & 8 & 7 \\
50 & 9 & 8 \\
Ofloxacin $(5 \mathrm{mcg})$ & 8 & 12 \\
\hline
\end{tabular}

sanctum leaves has been found to be largely responsible for the plants therapeutic potential (Prakash \& Gupta, 2005). Its antibacterial effect was evidenced by the value of diameter of zone of inhibition. The inhibition zone for different concentrations is shown in Table 2. From the table, it is found that $E$. coli and $S$. aureus are sensitive to silver nanoparticles. The observed value from the inhibition zone is in good agreement with previous reported studies (Abishek \& Amruthaa, 2013).

\section{Conclusion}

The reduction of silver to silver nanoparticles from green synthesis using tulsi leaves was carried out at room temperature. The green synthesis method from plant extract provides simple, efficient and good control over synthesized nanoparticles. Biosynthesized silver nanoparticles in an organic polymer (PVA) matrix were characterized using UV-vis, XRD, FTIR and SEM spectroscopic techniques. The presence of silver was evidenced using UV spectrum. From XRD studies, the peak reveals the presence of organic substance and silver nanoparticles, which was again confirmed by the FTIR spectrum. The SEM images show the presence of spherical shaped silver present inside a sponge-like PVA matrix. The presence of silver and iron was observed from the EDAX studies. The investigation on the antibacterial effect of nano-sized silver against $E$. coli and $S$. aureus reveals PVA encapsulated silver nanoparticles as a strong antibacterial agent. The synthesized silver nanoparticles can show new pathways in various fields like water purification, anticancer studies and drug delivery systems. 


\section{Conflict of interest}

The authors have no conflicts of interest to declare.

\section{References}

Abishek, S., \& Amruthaa, S. (2013). Green synthesis of silver nanoparticles from Psidium guajava extract and study of antibacterial activity. International Journal of Frontiers in Science and Technology, 1, 145-152.

Abdulrahman, H. B., Krajczewski, J., Aleksandrowska, D., \& Kudelski, A. (2015). Silica-protected hollow silver and gold nanoparticles: New material for Raman analysis of surfaces. The Journal of Physical Chemistry C, 119(34), 20030-20038.

Agnihotri, S., Mukherji, S., \& Mukherji, S. (2012). Antimicrobial chitosan-PVA hydrogel as a nanoreactor and immobilizing matrix for silver nanoparticles. Applied Nanoscience, 2(3), 179-188

Ahmad, A., Mukherjee, P., Senapati, S., Mandal, D., Khan, M. I., Kumar, R., \& Sastry, M. (2003). Extracellular biosynthesis of silver nanoparticles using the fungus Fusarium oxysporum. Colloids and Surfaces B: Biointerfaces, 28(4), 313-318.

Ahmed, T. A., \& Aljaeid, B. M. (2016). Preparation, characterization, and potential application of chitosan, chitosan derivatives, and chitosan metal nanoparticles in pharmaceutical drug delivery. Drug Design, Development and Therapy, 10, 483-507.

Atiyeh, B. S., Costagliola, M., Hayek, S. N., \& Dibo, S. A. (2007). Effect of silver on burn wound infection control and healing: Review of the literature. Burns, 33(2), 139-148.

Bhaumik, J., Thakur, N. S., Aili, P. K., Ghanghoriya, A., Mittal, A. K., \& Banerjee, U. C. (2015). Bioinspired nanotheranostic agents: Synthesis, surface functionalization, and antioxidant potential. ACS Biomaterials Science \& Engineering, 1(6), 382-392.

Callegari, A., Tonti, D., \& Chergui, M. (2003). Photochemically grown silver nanoparticles with wavelength-controlled size and shape. Nano Letters, 3(11), 1565-1568.

Chauhan, R. P., Gupta, C., \& Prakash, D. (2012). Methodological advancements in green nanotechnology and their applications in biological synthesis of herbal nanoparticles. International Journal of Bioassays, 1(07), 6-10.

Cheng, K. M., Hung, Y. W., Chen, C. C., Liu, C. C., \& Young, J. J. (2014). Green synthesis of chondroitin sulfate-capped silver nanoparticles: Characterization and surface modification. Carbohydrate Polymers, 110, 195-202.

Chen, X., \& Schluesener, H. J. (2008). Nano silver: A nano product in medical application. Toxicology Letters, 176(1), 1-12.

Dimitrijevic, N. M., Bartels, D. M., Jonah, C. D., Takahashi, K., \& Rajh, T. (2001). Radiolytically induced formation and optical absorption spectra of colloidal silver nanoparticles in supercritical ethane. The Journal of Physical Chemistry B, 105(5), 954-959.

Dobson, J. (2006). Gene therapy progress and prospects: Magnetic nanoparticlebased gene delivery. Gene Therapy, 13(4), 283-287.

Guirguis, O. W., \& Moselhey, M. T. (2012). Thermal and structural studies of poly (vinyl alcohol) and hydroxypropyl cellulose blends. Natural Science, 4(1), 57-67.

Hewakuruppu, Y. L., Dombrovsky, L. A., Chen, C., Timchenko, V., Jiang, X., Baek, S., \& Taylor, R. A. (2013). Plasmonic "pump-probe" method to study semi-transparent nanofluids. Applied Optics, 52(24), 6041-6050.

Huang, J., Li, Q., Sun, D., Lu, Y., Su, Y., Yang, X., . ., \& Hong, J. (2016). Biosynthesis of silver and gold nanoparticles by novel sundried Cinnamomum camphora leaf. Nanotechnology, 18(10), 105104.

Kang, Y. S., Risbud, S., Rabolt, J. F., \& Stroeve, P. (1996). Synthesis and characterization of nanometer-size $\mathrm{Fe}_{3} \mathrm{O}_{4}$ and $\gamma-\mathrm{Fe}_{2} \mathrm{O}_{3}$ particles. Chemistry of Materials, 8(9), 2209-2211.

Kim, J. H., Kim, J. Y., Lee, Y. M., \& Kim, K. Y. (1992). Properties and swelling characteristics of cross-linked poly(vinyl alcohol)/chitosan blend membrane. Journal of Applied Polymer Science, 45(10), 1711-1717.

Krasovskii, V. I., \& Karavanskii, V. A. (2008). Surface plasmon resonance of metal nanoparticles for interface characterization. Optical Memory and Neural Networks, 17(1), 8-14.
Mittal, A. K., Chisti, Y., \& Banerjee, U. C. (2013). Synthesis of metallic nanoparticles using plant extracts. Biotechnology Advances, 31(2), 346-356.

Mody, V. V., Siwale, R., Singh, A., \& Mody, H. R. (2010). Introduction to metallic nanoparticles. Journal of Pharmacy and Bioallied Sciences, 2(4), 282-289.

Naik, R. R., Stringer, S. J., Agarwal, G., Jones, S. E., \& Stone, M. O. (2002) Biomimetic synthesis and patterning of silver nanoparticles. Nature Materials, 1, 169-172.

Pankhurst, Q. A., Connolly, J., Jones, S. K., \& Dobson, J. J. (2003). Applications of magnetic nanoparticles in biomedicine. Journal of Physics D: Applied Physics, 36(13), R167-R181.

Park, T. J., Lee, K. G., \& Lee, S. Y. (2016). Advances in microbial biosynthesis of metal nanoparticles. Applied Microbiology and Biotechnology, 100(2), 521-534.

Philip, D., \& Unni, C. (2011). Extracellular biosynthesis of gold and silver nanoparticles using Krishna tulsi (Ocimum sanctum) leaf. Physica E: Lowdimensional Systems and Nanostructures, 43(7), 1318-1322.

Prakash, P., \& Gupta, N. (2005). Therapeutic uses of Ocimum sanctum Linn (Tulsi) with a note on eugenol and its pharmacological actions: A short review. Indian Journal of Physiology and Pharmacology, 49(2), 125-131.

Qin, Y. (2005). Silver-containing alginate fibres and dressings. International Wound Journal, 2(2), 172-176.

Rudge, S., Peterson, C., Vessely, C., Koda, J., Stevens, S., Catterall, L., Rudge, S., Peterson, C., \& Vessely, C. (2001). Absorption and deabsorption of chemotherapeutic drugs from a magnetically target carrier (MTC). The Journal of Controlled Release, 74, 335-340.

Sharma, V. K., Yngard, R. A., \& Lin, Y. (2009). Silver nanoparticles: Green synthesis and their antimicrobial activities. Advances in Colloid and Interface Science, 145(1), 83-96.

Sharma, H., Vendamani, V. S., Pathak, A. P., \& Tiwari, A. (2015). Fraxinus paxiana bark mediated photosynthesis of silver nanoparticles and their size modulation using swift heavy ion irradiation. Radiation Physics and Chemistry, 117, 184-190.

Salunke, B. K., Sawant, S. S., Lee, S. I., \& Kim, B. S. (2016). Microorganisms as efficient biosystem for the synthesis of metal nanoparticles: Current scenario and future possibilities. World Journal of Microbiology and Biotechnology, 32(5), 1-16

Sun, Y., Yin, Y., Mayers, B. T., Herricks, T., \& Xia, Y. (2002). Uniform form silver nanowire's synthesis by reducing $\mathrm{AgNO}_{3}$ with ethylene glycol in presence of seeds and poly(vinyl pyrolidine). Chemistry of Materials, 14(11) 4736-4745.

Sun, Y., \& Xia, Y. (2002). Shape-controlled synthesis of gold and silver nanoparticles. Science, 298(5601), 2176-2179.

Taylor, R., Coulombe, S., Otanicar, T., Phelan, P., Gunawan, A., Lv, W., ..., \& Tyagi, H. (2013). Small particles, big impacts: A review of the diverse applications of nanofluids. Journal of Applied Physics, 113(1), 011301.

Taylor, R. A., Otanicar, T., \& Rosengarten, G. (2012). Nanofluid-based optical filter optimization for PV/T systems. Light: Science \& Applications, 1(10), e34.

Taylor, R. A., Otanicar, T. P., Herukerrupu, Y., Bremond, F., Rosengarten, G., Hawkes, E. R., .. ., \& Coulombe, S. (2013). Feasibility of nanofluid-based optical filters. Applied Optics, 52(7), 1413-1422.

Valente, J. F. A., Gaspar, V. M., Antunes, B. P., Countinho, P., \& Correia, I. J. (2013). Microencapsulated chitosan-dextran sulfate nanoparticles for controled delivery of bioactive molecules and cells in bone regeneration. Polymer, 54(1), 5-15.

Yahyaei, B., Peyvandi, N., Akbari, H., Arabzadeh, S., Afsharnezhad, S. Ajoudanifar, H., \& Pourali, P. (2016). Production, assessment, and impregnation of hyaluronic acid with silver nanoparticles that were produced by Streptococcus pyogenes for tissue engineering applications. Applied Biological Chemistry, 59(2), 227-237.

Yin, B., Ma, H., Wang, S., \& Chen, S. (2003). Electrochemical synthesis of silver nanoparticles under protection of poly(N-vinylpyrrolidone). The Journal of Physical Chemistry B, 107(34), 8898-8904.

Zhang, F., Wu, X., Chen, Y., \& Lin, H. (2009). Application of silver nanoparticles to cotton fabric as an antibacterial textile finish. Fibers and Polymers, 10(4), 496-501. 